\title{
In Defense of Regulated Fee-for-Service Payment: A Response to Recent Commentaries
}

\author{
Naoki Ikegami*
}

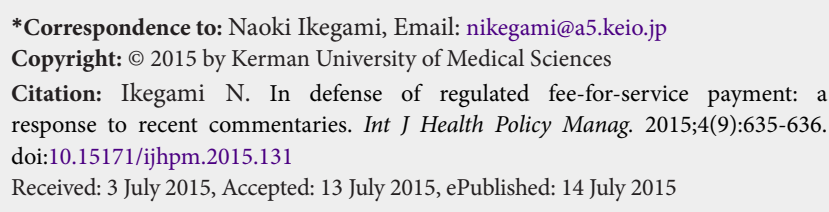

I $\mathrm{n}$ health policy, magic bullet answers tend to have more appeal than incremental adjustments. Politicians faced with the daunting issues in healthcare are eager to embrace new ideas promoted by academics and think tanks. However, in implementation, intrinsic flaws in design, such as the difficulty of finding physicians willing to be at risk for the costs of care, tend to be ignored. Once launched, inconvenient data about cost savings and quality tend to be downplayed or ignored until intrinsic flaws become manifest, ${ }^{1}$ which would be the signal to embrace a new idea. Such is likely to be the fate of the latest fix-all from the United States: the Accountable Care Organizations (ACOs).

This was one reason why I wrote my editorial ${ }^{2}$ : to explain why it would be better to regulate fee-for-service (FFS) payment, the traditional way by which physicians have been paid, rather than attempting to introduce capitation in primary care and diagnosis-related groups (DRGs) in inpatient care. Although Britton has pointed out that a regulating process is needed in all methods of payment, ${ }^{3}$ DRG and pay-for-performance (P4P) require more administrative capacity. This makes it difficult for most low- and middle-income countries (LMIC) where payment tends to be dichotomized into line-item budgets for the public sector and unregulated FFS for the private sector. Moreover, in the former, patients tend to be charged for services not covered (extra billing) and/or charged for services that are covered (balance billing).

To regulate FFS payment, medical procedures must first be classified and defined. Second, to conduct surveys of the volume of each item being currently delivered. Third, to assign relative weights to each item based on opinions of professional groups concerning the time and other resources needed. Fourth, for the public sector, to set fees based on the relative weight and volume of each item by allocating from the budget. For the private sector, the fees could initially be set several times higher than that of the public sector but using the same relative scale. Finally, to gradually decrease the difference in amount between the two sectors. Be doing so, the two sectors could eventually be integrated, which will lead not only to greater equity, but also to greater efficiency. Note that it would be a futile exercise to conduct extensive cost studies because resources used, and therefore costs, differ considerably across settings. Moreover, half of health expenditures relate to labor costs but there is no consensus on the appropriate hourly income of physicians (or that of nurses and other staff) when compared with other workers.

Britton states that the regulatory mechanism would be greatly strengthened by introducing electronic medical records (EMRs). I agree that EMR would improve the quality of care and electronic billing will increase efficiency. However, I would be very cautious of directly linking EMR with data used for claims purposes because it would make gaming easier. For example, based on computerized algorithms, there could be prompts on the screen for physicians to add diagnoses or to order laboratory and diagnostic tests, backed up by questions to be posed to patients with options for their response. In this way, billing could be padded, yet with all regulations complied, by the physician making a few clicks.

To respond categorically to the points raised by Koppel ${ }^{4}$ :

1. Preventing doctors from working outside of the system: If only governments in LMIC could do so by paying them "adequate" wages! Even in high-income countries in Europe, higher level physicians are usually allowed to receive FFS payment when practicing in the private sector.

2. The repeated failure of setting reasonable cost rates in the United States: It is the United States which is the outlier among high-income countries. Other countries have succeeded, at least when compared with the United States, as evidenced by their lower medical expenditures.

3. \& 4. Medical device costs and new technology not driven down by competition: I had assumed that prices are uniformly regulated. In Japan, in the 2002 fee schedule revision, magnetic resonance imaging (MRI) fees were reduced by $30 \%$. One justification for doing so was that competition had driven down the purchasing price of a MRI (list prices are a fiction). In the 2006 revision, their fees were differentiated according to the imaging density: a higher fee for images taken by a MRI with more than 1.5 Tesla, and a lower fee for those less. ${ }^{5}$ When purchasing a car, luxury cars are priced higher than compacts. When a model change is announced, the dealer will reduce the price of the old model. The same principle should apply when purchasing a MRI.

The staff of international agencies and authors of academic journals tend to be dominated by Americans and British, who 
have imposed their paradigms in healthcare. My editorial was written to remedy this imbalance.

Ethical issues

Not applicable.

Competing interests

Author declares that he has no competing interests.

Author's contribution

$\mathrm{NI}$ is the single author of the manuscript.

\section{References}

1. Introcaso D, Gaus C. Medicare's rush to risk: Confounding theory and practice, leaving ACOs vulnerable. http:// healthaffairs.org/blog/2015/06/19/medicares-rush-to-riskconfounding-theory-and-practice-leaving-acos-vulnerable/print.
Published June 19, 2015.

2. Ikegami N. Fee-for-service payment-an evil practice that must be stamped out? Int J Health Policy Manag. 2015;4:57-59. doi:10.1517/ijhpm.2015.26

3. Britton JR. Healthcare reimbursement and quality improvement: Integration using the electronic medical record. Int $J$ Health Policy Manag. 2015;4:forthcoming. doi:10.15171/ijhpm.2015.93

4. Koppel R. Two wrongs do not make a right: flaws in alternatives to fee-for-service payment plans do not mean fee-for-service is a good solution to rising prices. Int J Health Policy Manag. 2015;4: forthcoming. doi:10.1517/ijhpm.2015.94

5. Ikegami N. Universal Health Coverage for Inclusive and Sustainable Development Lessons from Japan. http://documents. worldbank.org/curated/en/2014/09/20278271/universal-healthcoverage-inclusive-sustainable-development-lessons-japan. Published September 25, 2014. 